\title{
Calcium phosphate drug delivery system: influence of local zoledronate release on bone implant osteointegration
}

\author{
B. Peter ${ }^{\mathrm{a}}$, D.P. Pioletti ${ }^{\mathrm{a}, *}$, S. Laib ${ }^{\mathrm{b}}$, B. Bujoli ${ }^{\mathrm{b}}$, P. Pilet ${ }^{\mathrm{c}}$, P. Janvier ${ }^{\mathrm{b}}$, J. Guicheux $^{\mathrm{c}}$, \\ P.-Y. Zambelli ${ }^{\text {, J.-M. Bouler }}{ }^{\mathrm{c}}$, O. Gauthier ${ }^{\mathrm{c}}$ \\ a Bone Bioengineering Group, Laboratory of Orthopedic Research, Swiss Federal Institute of Technology Lausanne, Switzerland \\ ${ }^{\mathrm{b}}$ Laboratoire de Synthèse Organique UMR CNRS 6513, Faculté des Sciences, Nantes, France \\ ${ }^{\mathrm{c}}$ Laboratoire de Recherche sur les Materiaux d'Intérêt Biologique INSERM 99-03, Faculté de Chirurgie Dentaire, Nantes, France \\ ${ }^{\mathrm{d}}$ Hôpital Orthopédique de la Suisse Romande, Lausanne, Switzerland
}

Received 5 April 2004; revised 23 August 2004; accepted 12 October 2004

Available online 23 November 2004

\begin{abstract}
Despite total hip replacement (THR) gives generally satisfactory results, the quality of outcome in young patients is markedly decreased compared to the average THR outcome. For this population, pharmacological treatment with bisphosphonate would be beneficial to decrease the peri-implant osteolysis. However, as this population does not necessarily suffer from osteoporosis, a nonsystemic treatment would be preferable. Zoledronate was then grafted to hydroxyapatite (HA) coating of titanium implants. The implants were inserted in rat condyles with various zoledronate concentrations. A positive concentration-dependent effect was observed on the peri-implant bone density and on different histomorphometric parameters. Importantly for the outcome of the implants, the mechanical fixation was increased by the local presence of zoledronate.

The obtained results open the way of an easy transformation of currently existing HA-coated implants by grafting bisphosphonate onto the coating in order to increase their service life in the patients.
\end{abstract}

(C) 2004 Elsevier Inc. All rights reserved.

Keywords: Orthopedic implant; Drug delivery; Bisphosphonates; Biomechanics

\section{Introduction}

The hydroxyapatite (HA) coating has been used now in orthopedic surgery for over 15 years in cementless joint replacement [10]. Initially, it was developed to accelerate the peri-implant bone formation and thus decrease the time needed to obtain a secondary fixation of the implant. The initial fixation of the implant is crucial for the success of an implant [27]. Since then, it has been shown that the HA coating improves the stability of the implant, the interface strength, the bone mineralization, and the bone ingrowth rate [38]. Specifically, Adler et al. [1] showed that HA coating increased the fatigue resistance of the bone-implant

* Corresponding author. Bone Bioengineering Group, LRO, Bat AAB, EPFL, 1015 Lausanne, Switzerland. Fax: +41 216938660.

E-mail address: dominique.pioletti@epfl.ch (D.P. Pioletti). interface, while the migration of HA-coated acetabular cups was decreased as compared to uncoated cups [28]. However, the interface between the coating and the implant may become the weak point of the system [31]. This problem was solved by decreasing the HA coating thickness [41].

As shown in the Swedish National Hip Arthroplasty Register (SNHAR), cementless hip replacement survival is as low as $75 \%$ in young patients after 10 years. Recently, one way that was suggested to increase the lifetime of such implants, was to use bisphosphonate [37]. The basic idea was to decrease the primary failure mode which is aseptic loosening following peri-implant osteolysis [14]. These drugs are already successfully used in the treatment of osteoporosis [12]. Bisphosphonates, such as ibandronate [11], EDPH [32], zoledronate [3], TRK-530 [19], and alendronate [43], have been extensively studied and demonstrated their antiresorptive effect. 
The classic bisphosphonate treatment is the systemic way by oral administration or intravenous injection. Different studies have shown the positive effect of systemic bisphosphonate treatment in protecting the peri-implant bone, either around cemented [15] or around uncemented implants [42]. However, side effects like fever [29,40], throat, or stomach ulcers [9] as well as a low bioavailability [16] are generally observed for systemic bisphosphonate treatment. In order to avoid these adverse effects and to increase the bisphosphonate bioavailability, the systemic treatment following a total hip replacement (THR) could be replaced by a local delivery with the implant selectively coated with bisphosphonate. The bone in contact with the implant will be the only part of the skeleton being exposed to the drug. This is important as patients undergoing THR do not necessarily present osteoporosis.

Few studies have tried to evaluate the effect of local bisphosphonate delivery with implant. The local drug delivery approach has been tested in vivo with no negative effects but only slight increase in implant osteointegration for dental implants $[25,26]$ or for bulk hydroxyapatite blocks [7,8]. Recently, Yoshinari et al. [44] used plasmasprayed HA-coated titanium dental implant which were immersed in pamidronate and implanted in beagle mandibular bone. This study showed a $10 \%$ increase in bone contact area. Tengvall et al. [39] showed a $28 \%$ increase in pullout force and $90 \%$ pullout energy when comparing stainless steel screws with the same type of screws but coated with a fibrinogen coating containing pamidronate and implanted in rat tibia. In the limit of our knowledge, no information can be found about the optimal bisphosphonate quantity needed to achieve an increase specifically in fixation of orthopedic implant.

We aim at determining whether zoledronate locally released from an HA-coated implant could increase the mechanical fixation of metallic implant in bones. Therefore, the study explores the zoledronate concentration range to determine which concentration leads to the optimal bone density distribution around the implant, optimal distribution being defined as the distribution that leads to the highest mechanical stability of the implant as determined by the maximal pullout force. Moreover, the changes in the bone structure were also assessed using histomorphometric measurements.

\section{Materials and methods}

\section{Animals}

Twenty female 6-month-old Wistar rats were used for this experiment. The rats are all mature. The animals had free access to normal diet. The animals were randomly separated in five groups representing the different zoledronate concentrations in the HA coating: 0, 0.2, 2.1, 8.5, and $16 \mu \mathrm{g} /$ implant.
The column "Rats" in Table 1 shows the number of rats implanted for this study. Three rats belonging to different groups died of causes unrelated to the study. Each rat received two implants containing the same zoledronate concentration, one in each condyle. For each animal, one condyle was used for density measurement and histomorphometric measurements, while the contralateral condyle was used for the pullout test. The columns "SEM" and "Histomorphometry" in Table 1 give the number of femurs used for these tests, and in parenthesis, the total number of slides obtained. The column "Pullout" gives the number of condyles tested for each condition. Some femurs could not be used for the pullout test because the condyles were damaged during tissue removal.

\section{Metal implants and zoledronate}

Titanium alloy (TA6V) cylinders (diameter $3 \mathrm{~mm}$; length $5 \mathrm{~mm}$ ) were plasma-coated with hydroxyapatite (thickness: $20 \mu \mathrm{m}$; crystallinity index $62 \%$ ).

Zoledronate (1-hydroxy-2-[(1H-imidazole-1-yl)ethylidene] 1-bisphosphonic acid disodium salt) was supplied by Novartis Pharmaceuticals AG, Basel, Switzerland.

\section{Grafting of zoledronate}

The chemical association of zoledronate with the HA coating was carried out by soaking the implants in zoledronate solution in ultrapure water. No stirring of the reaction vessel was performed to prevent any mechanical erosion of the HA coating. Typically, 19 implants were immersed for $48 \mathrm{~h}$ in $5 \mathrm{ml}$ of aqueous zoledronate solutions of variable concentration: $2.2510^{-6}, 2.2510^{-5}$, $2.2510^{-4}$, and $2.2510^{-3} \mathrm{~mol}^{-1}$, leading to modified coatings. Then, the remaining amount of zoledronate in the supernatant at the end of the reaction was determined as previously described [20], using a protocol based on the Ames method [2] for the determination of the phosphorus content in solution. By difference with the initial amount of zoledronate present in solution, the zoledronate loading onto the implants was deduced, namely, 1.9-2.4 $\mu \mathrm{g}$ zoledronate per implant (corresponding to a full incorporation of zoledronate), $8-9 \mu \mathrm{g}$ zoledronate per implant (corresponding to a 35\% incorporation ratio), and $16 \mu \mathrm{g}$ zoledronate per implant (corresponding to a 7\% incorporation ratio). All the zoledronate-association experiments

Table 1

Number of rats per condition and femurs (slices) per test

\begin{tabular}{lllll}
\hline Conditions & Rats & SEM & Histomorphometry & Pullout \\
\hline Control & 4 & $3(18)$ & $3(18)$ & 2 \\
$0.2 \mu \mathrm{g} /$ implant & 4 & $2(28)$ & $2(28)$ & 1 \\
$2.1 \mu \mathrm{g} /$ implant & 4 & $4(32)$ & $4(32)$ & 3 \\
$8.5 \mu \mathrm{g} /$ implant & 4 & $4(33)$ & $4(33)$ & 4 \\
$16 \mu \mathrm{g} /$ implant & 4 & $4(21)$ & $4(21)$ & 3 \\
\hline
\end{tabular}


were repeated twice, leading to reproducible results. Due to the detection limit of our method, the zoledronate loading for the lowest grafting concentration could not be measured. Taking account of the data described above, however, it is reasonable to assume that zoledronate was quantitatively incorporated, with a value of $0.2 \mu \mathrm{g}$ per implant. The presence of zoledronate on the modified implants was investigated in the case of the coating loaded with $16 \mu \mathrm{g} / \mathrm{implant;}$ for that purpose, the calcium phosphate coating was removed from the implant, and a solid state 31P CP-MAS NMR spectrum of the resulting powder clearly showed a weak signal in the expected range for zoledronate (10-20 ppm), along with the resonance corresponding to the calcium phosphate (2.7 [strong] and 6 [weak] ppm). Using an SEM, no alteration of the coating due to the grafting process could be measured.

\section{Surgical protocol}

The protocol for the animal experiment was approved by the local Ethical Committee for Animal studies of the National Veterinary School of Nantes. Animals were kept at the Experimental Surgery Laboratory of the Nantes University according to European Community guidelines for the care and use of laboratory animals (DE86/609/CEE).

Surgical procedures were conducted under general anesthesia using intraperitoneal injection of sodium thiopental associated with subcutaneous injection of morphine sulfate. Bilateral implantations were performed at the distal end of the femurs, at the epiphysometaphyseal junction. After lateral arthrotomy of the knee joint, the lateral condyle was exposed and drilled perpendicularly to the long axis of the femur. The drilling procedure was performed with two successive bits $(2.2$ and $2.8 \mathrm{~mm}$ in diameter) on a low-speed rotative dental handpiece and under sterile saline irrigation. Hemostasis of the bone cavity was controlled with sterile gauges, and the coated implant was then gently inserted into the cavity under digital pressure. The surgeon was blinded for the treatment. Articular and cutaneous tissues were closed in two separate layers. After surgery, all the animals were allowed to move freely in their cages.

Animals were killed 3 weeks after implantation by intracardiac injection of overdosed sodium pentobarbital, after induction of intraperitoneal general anesthesia. Using a $\mu-\mathrm{CT}$, it was established that the position of the implant in the condyle was similar for all animals.

\section{SEM sample preparation}

The femoral ends were then immediately dissected, fixed in glutaraldehyde solution, and stored in a $4 \%$ paraformaldehyde, $0.1 \%$ glutaraldehyde in $0.08 \mathrm{M}$ cacodylate buffer.
Using a handpiece, the condyle was sawed off $1 \mathrm{~cm}$ above the implant. The sample was dehydrated in a series of alcohol solutions. The first impregnation step was to soak the sample in a mixture of $50 \%$ alcohol $100^{\circ}$ and $50 \%$ methyl methacrylate MMA (Fluka Chemika, Sigma Aldrich Chemie Gmbh, Steinheim, Germany) during 24 h. The second impregnation step was to soak the sample in pure MMA during $24 \mathrm{~h}$.

The first inclusion step was to soak the dehydrated sample during $2 \mathrm{~h}$ under vacuum in a solution containing 90\% MMA, 10\% dibutylphtalate (Fluka Chemika) and 1\% benzoyl peroxide (Fluka Chemika). The sample was then removed from the solution and soaked in the same solution but enhanced by a polymerization activator (N,N-dimethyl$p$-toluidine) (Fluka Chemika). The polymerization took place at $-20^{\circ} \mathrm{C}$ and was complete after $48 \mathrm{~h}$.

The samples were cut in slices $100 \mu \mathrm{m}$ thick using a Microtome saw 1600 (Leica, Nussloch, Germany) diamond saw. The cutting plane was perpendicular to the implant.

\section{SEM}

The slices were carbon-coated. The samples were then observed in a JEOL JSM 6300 scanning electron microscope (JEOL, Tokyo, Japan) using the backscattered electron detector allowing to distinguish mineralized bone from soft tissue. Each sample was observed at two different magnifications: $10 \times$ and $23 \times$. These two magnifications were chosen to assess the influence of the biocoating close to the implant and further away.

Using Quantimet (Zeiss, Jena, Germany), the bone density and bone surface were measured as a function of the distance from the surface of the implant up to a distance of $200 \mu \mathrm{m}$ on the pictures taken at a magnification of $23 \times$. By surface of the implant means the external side of the coated titanium cylinder. The bone density is defined as the ratio of the white surface of the examined area divided by the total surface of the examined area.

\section{Histomorphometry}

A number of histomorphometric parameters have been measured, and the following parameters [6] were influenced by the biocoating: mean length of terminus-toterminus struts (Tm.Tm/TSL), mean length of node-toterminus struts $(\mathrm{Nd} . \mathrm{Tm} / \mathrm{TSL})$, node to termini ratio (Nd.Tm), mean length of node to node struts (Nd.Nd/ TSL), number of termini in the calcified skeleton (N.Tm), and total strut length (TSL). The calculations were performed using a home-written procedure with Quantimet (Zeiss) language and are described by Chappard et al. [6]. The trabecular bone at depth between 1 and $4 \mathrm{~mm}$ was used to calculate the histomorphometric parameters. The parameters were calculated as a function of zoledronate concentration. 


\section{Pullout sample preparation}

After careful removal of all tendons and other soft tissues around the emerging part of the implant, a mould was made out of PMMA for each bone, in order to evenly distribute the stresses and so safely pull out the implant from the condyle.

\section{Pullout test}

A tensile testing machine (Instron, Canton, USA) equipped with a 1000-N gauge was used. The implants were pulled with a steady speed of $1 \mathrm{~mm} / \mathrm{min}$. Displacement versus force was registered and used for the determination of the maximal pullout force.

\section{Statistics}

The number of slices per animal were accounted for as repetition of the density measurement of the same animal. One-way ANOVA and Fisher test were used to determine the statistical significance of differences in the results. A probability value of $P \leq 0.05$ was considered to be statistically significant.

\section{Results}

The SEM pictures shown in Fig. 1 clearly illustrate from a qualitative point of view the positive effect of zoledronate HA-coated implants on the peri-implant bone density. Figs. $1 \mathrm{a}$ and $\mathrm{b}$ show the peri-implant bone distribution around the implant HA-coated either nongrafted with zoledronate or grafted with $2.1 \mu \mathrm{g}$, respectively. Figs. 1c and d show a more detailed view of the peri-implant bone without or with zoledronate, respectively. The bone density around the implant containing 2.1 $\mu \mathrm{g}$ of zoledronate is clearly higher and localized in the vicinity of the implant.

Fig. 2 shows the bone density as a function of zoledronate concentration in the coating and the distance from the surface of the implant. In the first $20 \mu \mathrm{m}$ around the implant, three behaviors can be observed. First, the two lowest zoledronate concentrations ( 0.2 and $2.1 \mu \mathrm{g}$ /implant) result in the highest bone densities with a steep decrease with increasing distance from the implant, but still above all the other cases $(P<0.01)$. Second, the implant loaded with $8.5 \mu \mathrm{g} /$ implant shows a lower $(P<0.02)$ but steadier density than the two cases described above. Third, the bone density around the implant either loaded with the highest zoledronate concentration (16 $\mu \mathrm{g} / \mathrm{implant})$ or the implant without zoledronate shows the lowest density. These two cases are statistically not different from each other. Nevertheless, these two cases follow different trends. Bone density around the implant without zoledronate is decreasing, while the bone density around the implant containing $16 \mu \mathrm{g} / \mathrm{implant}$ zoledronate is increasing as a function of distance.

Between 40 and $80 \mu \mathrm{m}$, the situation changes. The highest bone density is obtained with an intermediate zoledronate concentration ( $2.1 \mu \mathrm{g} /$ implant $)$. The bone around the implant loaded with $0.2 \mu \mathrm{g} /$ implant becomes less dense than the bone around the implant loaded with $8.5 \mu \mathrm{g} / \mathrm{implant}$, thus inverting the situation observed closer to the implant. The implant without any zoledronate induces the lowest density $(P<0.01)$, about $30 \%$ lower than the lowest bone density obtained with the zoledronate-loaded implants. The implant containing the highest zoledronate concentration constantly increases the bone density which reaches the same density as the bone around the implant containing $0.2 \mu \mathrm{g} / \mathrm{implant}$.

From 80 to $200 \mu \mathrm{m}$, the bone density around the coatings containing zoledronate from 2.1 to $16 \mu \mathrm{g}$ /implant converges to a common density comprised between 0.62 and 0.64 . The zoledronate-free implants induce a constant relative bone density of 0.35 which is statistically different from the zoledronate-containing cases $(P<0.01)$. The density of the bone growing around the coatings containing $0.2 \mu \mathrm{g}$ zoledronate is constant at 0.52 and statistically

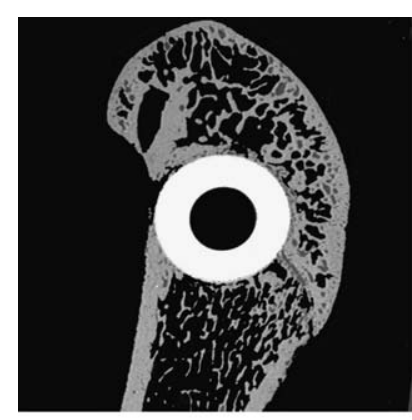

(a) $0 \mu \mathrm{g}$ zoledronate per implant 10x

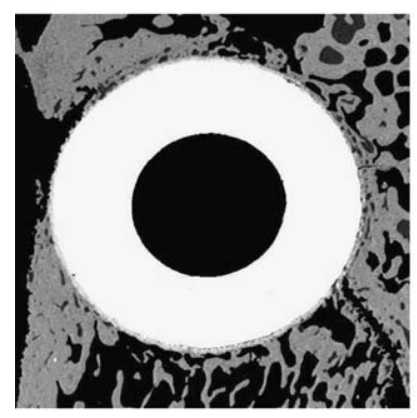

(c) $0 \mu \mathrm{g}$ zoledronate per implant $23 \mathrm{x}$

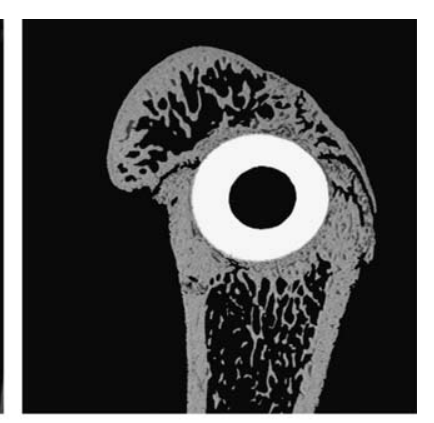

(b) $2.1 \mu \mathrm{g}$ zoledronate per implant 10x

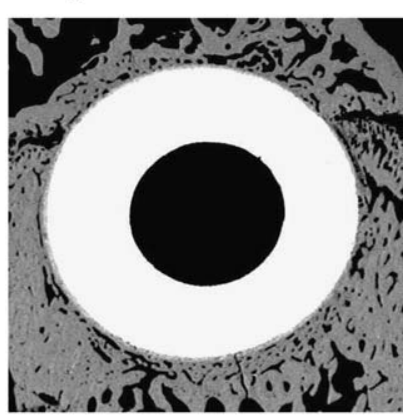

(d) $2.1 \mu \mathrm{g}$ zoledronate per implant $23 \mathrm{x}$
Fig. 1. SEM pictures of two implanted condyles at magnification of $10 \times$ and $23 \times$. Panel a shows the bone structure of a condyle implanted with a coated implant containing no zoledronate, and panel $\mathrm{b}$ shows the bone structure of the condyle containing an implant coated with HA grafted with $2.1 \mu \mathrm{g}$ of zoledronate. The same implants and their peri-implant bone are shown in panels $\mathrm{c}$ and $\mathrm{d}$ for the coatings loaded with $0 \mu \mathrm{g}$ and $2.1 \mu \mathrm{g}$ of zoledronate, respectively, at a magnification of $23 \times$. 


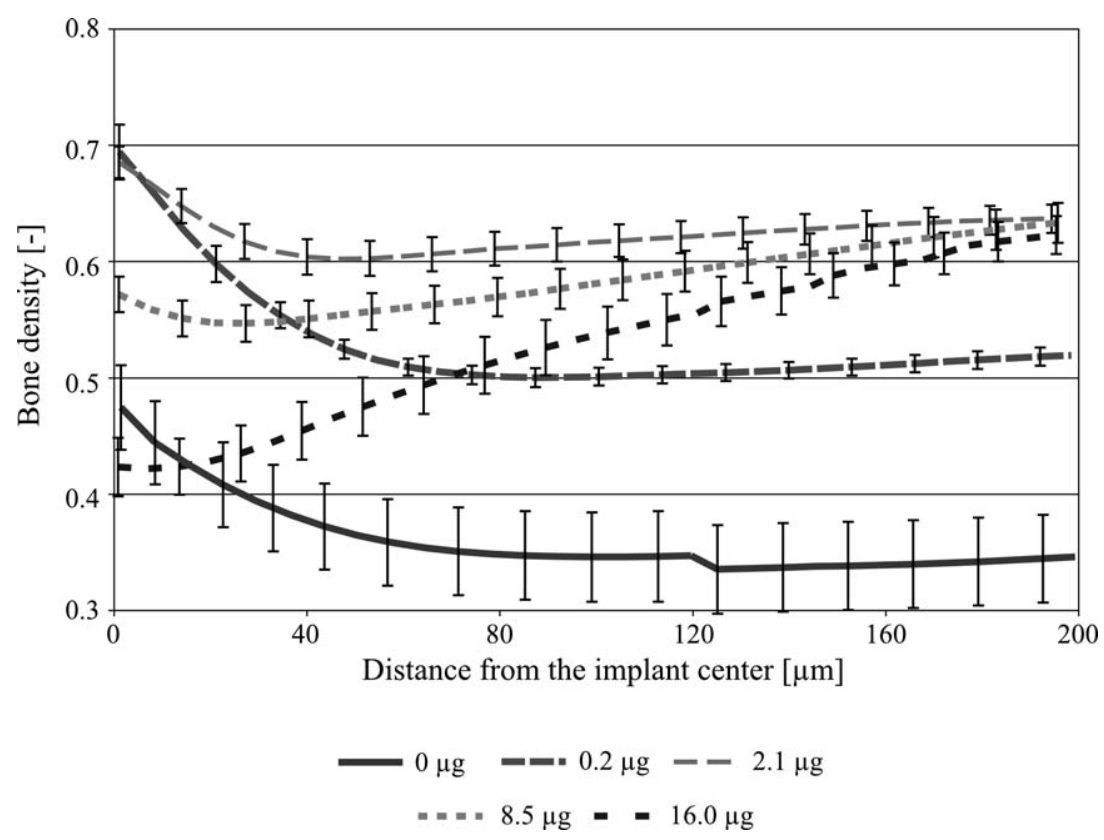

Fig. 2. Bone density as function of condition ( $\mu \mathrm{g} / \mathrm{implant})$ and distance from implant surface (mean $\pm \mathrm{SEM}$ ). Close to the implant, the peri-implant bone density is the highest when 0.2 and $2.1 \mu \mathrm{g}$ of zoledronate are present in the coating. When higher zoledronate quantities are present in the coating, the density decreases until reaching the same level as when no zoledronate is present. At $200 \mu \mathrm{m}$ from the implant, the peri-implant bone density is the highest when 2.1 to $16 \mu \mathrm{g}$ zoledronate are present in the coating. An intermediate density level is obtained with $0.2 \mu \mathrm{g} / \mathrm{implant}$, while the lowest density is reached when no zoledronate is present.

different from the other zoledronate-containing implants $(P<0.028)$.

The maximal pullout force (Fig. 3) increases with increasing zoledronate concentration up to $2.1 \mu \mathrm{g} / \mathrm{implant}$. At higher doses, the maximal pullout force decreases with increasing zoledronate concentration. Statistically, the coating containing $2.1 \mu \mathrm{g}$ zoledronate reaches a significantly higher pullout force than the case containing $8.5 \mu \mathrm{g}(P=$ $0.02)$ and the case containing $16 \mu \mathrm{g}(P=0.023)$. Due to low number of specimens tested, no statistical difference could be shown between the other cases.

Zoledronate presence influences four histomorphometric parameters (Tm.Tm/TSL, Nd.Tm/TSL, Nd.Nd/TSL, total strut length) in a concentration-dependent manner, while two parameters $(\mathrm{Nd} . \mathrm{Tm}$ and N.Tm) are influenced only by one concentration (Fig. 4). Tm.Tm/TSL, Nd.Tm/ TSL, and Nd.Nd/TSL are decreasing with increasing zoledronate concentration. Statistically two groups become visible: at concentrations of 0.2 and $2.1 \mu \mathrm{g} /$ implant, the parameters are close to control, while at higher zoledronate concentrations, Tm.Tm/TSL, Nd.Tm/ TSL, and Nd.Nd/TSL are lower.

TSL significantly increases with increasing zoledronate concentration. TSL of the bone exposed to $0.2 \mu \mathrm{g} / \mathrm{implant}$ is not statistically different from the case without zoledronate.

The parameters Nd.Tm and N.Tm show a different profile. In both cases, the values for the bone treated with $0.2 \mu \mathrm{g} / \mathrm{implant}$ are statistically different from all the other cases $(P<0.019)$.
Using a power law to fit the different histomorphometric parameters with the pullout maximum force, we obtained the correlation factors shown in Table 2. The parameters N.Tm and Nd.Tm did not show any correlation with the maximum pullout force $\left(R^{2}\right.$ of 0.22 and 0.21 , respectively). TSL,

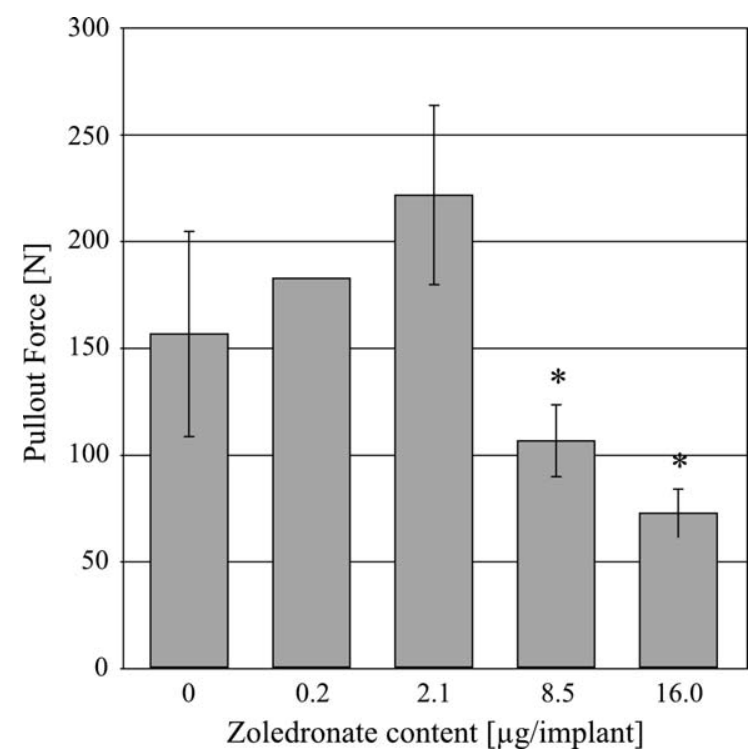

Fig. 3. Pullout force as function of zoledronate concentration (mean \pm SEM). At low zoledronate concentrations, the pullout force increases with increasing zoledronate content of the coating. The pullout force reaches a maximum with a zoledronate content of $2.1 \mu \mathrm{g} / \mathrm{implant}$. By further increasing the zoledronate content of the coating, the pullout force decreases and reaches levels lower than when no zoledronate is present. 


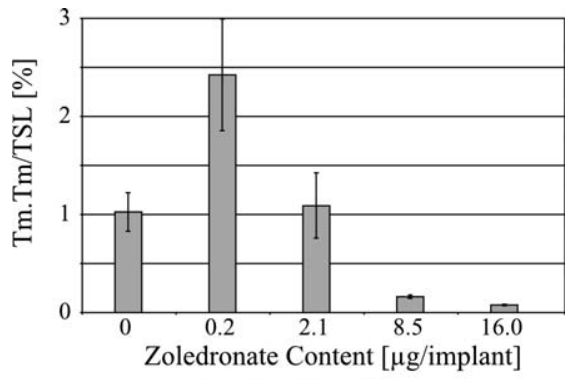

(a) Tm.Tm/TSL

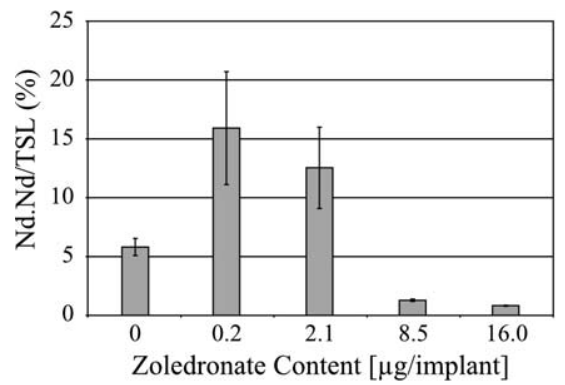

(c) $\mathrm{Nd} . \mathrm{Nd} / \mathrm{TSL}$

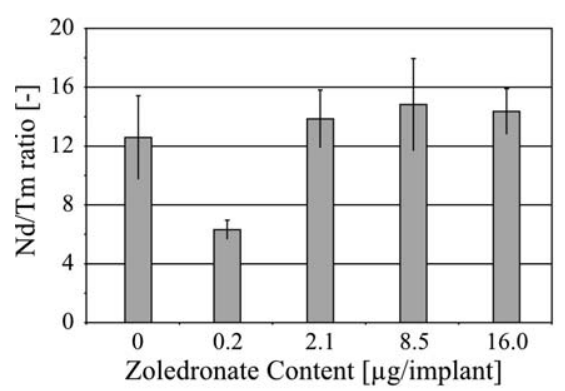

(e) $\mathrm{Nd} / \mathrm{Tm}$

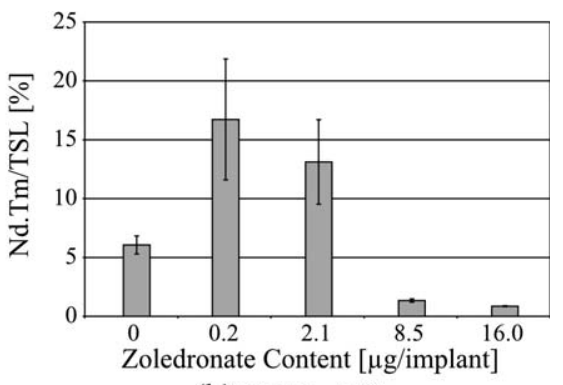

(b) Nd.Tm/TSL

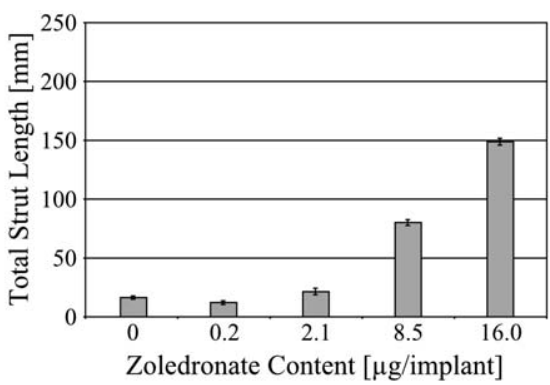

(d) TSL

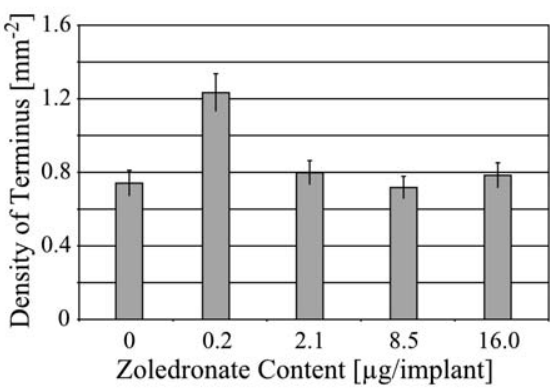

(f) N.Tm

Fig. 4. Histomorphometric parameters as function of conditions (mean \pm SEM). Four parameters are dose-dependently influenced by zoledronate. Tm.Tm/ TSL, Nd.Tm/TSL, and Nd.Nd/TSL are decreased by increasing zoledronate concentration. TSL is increased with the zoledronate content of the coating. Nd.Tm and N.Tm are only influenced by the coating containing $0.2 \mu \mathrm{g} /$ implant.

Nd.Nd/TSL, Nd.Tm/TSL, and Tm.Tm/TSL are strongly correlated to the maximum pullout force $\left(R^{2}\right.$ of $0.87,0.92$, 0.92 , and 0.86 , respectively).

\section{Discussion}

The goal of this study was to determine the zoledronate concentration leading to an optimal peri-implant bone

Table 2

Correlation factor of the histomorphometric parameters data fitted with the maximum pullout force by a power law

\begin{tabular}{ll}
\hline Parameter & $R^{2}$ \\
\hline N.Tm & 0.22 \\
Nd/Tm & 0.21 \\
TSL & 0.87 \\
Nd.Nd/TSL & 0.92 \\
Nd.Tm/TSL & 0.92 \\
Tm.Tm/TSL & 0.86 \\
\hline
\end{tabular}

density distribution, optimal from the point of view of implant fixation. The most remarkable result of this study was to show the existence of a window of zoledronate concentration ( 0.2 to $2.1 \mu \mathrm{g} / \mathrm{implant})$ in which the mechanical fixation of the implant is increased.

Tengvall et al. [39] showed an increase by $28 \%$ of the pullout force of steel screws inserted in rat femurs by using a fibrinogen/pamidronate/ibandronate coating. In the present study, the implants containing $2.1 \mu \mathrm{g}$ of zoledronate induced an increase in pullout force up to $42 \%$ compared to implants without zoledronate. This difference may be explained by the fact that zoledronate is more efficient in shifting the bone remodeling towards a positive balance than the bisphosphonates used by Tengvall et al. The combination of HA and zoledronate is probably more favorable than fibrinogen and bisphosphonate in the point of view of orthopedic implant fixation.

At higher zoledronate concentrations, the pullout force decreased by $35 \%$ when compared to implants without zoledronate. The decrease in mechanical stability of the 
implants, when high zoledronate quantities are present, might be correlated to the lower mineralized bone density close to the implant. Indeed, two situations are possible to explain the lower mineralization, either impairment of the mineralization itself or negative effect on osteoblast function. In this study, the bone mineral density was measured by detecting backscattered electrons using an SEM. As shown by some others [5,35], this methods allows to measure the bone mineralization. However, it was not possible to determine if mineralization itself was impaired by the presence of zoledronate. In a previous study, it has been shown that alendronate has only small effects on the bone mineralization [13]. This might also be the case for zoledronate, but no conclusion can be obtained with the present study. However, high zoledronate concentrations may impair mineralization by affecting osteoblast function as suggested in previous in vitro studies [33,34].

A supporting observation to this hypothesis is the fact that in the first $20 \mu \mathrm{m}$ around the implant, the bone density is the same for the coating without zoledronate and the one containing the highest zoledronate quantity. Moreover, with increasing distance, the bone density around the implant loaded with the highest zoledronate concentration increases, whereas the bone density in case of zoledronate-free implants decreases. This behavior of the zoledronatecontaining implant is due to the dilution of the zoledronate with increasing distance. The abovementioned hypothesis also explains why the bone reaches the same density at 200 $\mu \mathrm{m}$ from the implants containing the three highest zoledronate concentration. It also explains why the implants with the two lowest zoledronate content $(0.2$ and $0 \mu \mathrm{g})$ are lower by $17 \%$ and by $45 \%$, respectively, compared to the highest density. These observations constitute an indirect evidence of the release and delivery of zoledronate in a local region around the $\mathrm{HA} /$ zoledronate-coated implants, although it does not rule out the possibility that the zoledronate transport is also carried out by the osteoclasts having ingested the bisphosphonate.

Since the peri-implant bone density and the maximum pullout force are influenced by the presence of zoledronate, a correlation may exist between bone density and mechanical stability. In fact, the correlation between the pullout force and the density of the bone taken at a distance of $3 \mu \mathrm{m}$ from the implant's surface is strong $\left(R^{2}=0.87\right)$. Interestingly, when the bone density is taken at a greater distance from the implant, the correlation decreases. At $20 \mu \mathrm{m}$, the correlation factor decreases to 0.77 and progressively to 0.49 at $58 \mu \mathrm{m}$. When the bone density used for the correlation calculation is taken at $200 \mu \mathrm{m}$, the correlation factor is as low as 0.02 . Thus, the first $20 \mu \mathrm{m}$ are of uttermost importance for the mechanical fixation of an implant. Thereby the approach of increasing the periimplant density by a local drug delivery becomes even more justified.

In most in vivo studies, the effect of bisphosphonates on the histomorphometry of bone was an increase in trabecular number and thickness and a decrease of trabecular separation $[18,24,30]$. In our study, none of those parameters seems to be altered by the presence of zoledronate. The parameters Tm.Tm/TSL, Nd.Tm/TSL, Nd.Nd/TSL, and TSL illustrate a narrowing of the network structure of trabecular bone. These differences may be explained by the different delivery methods. In the other studies, the bisphosphonate arrives through the blood into the bone, where it is distributed in the whole bone. Therefore, the drug will affect the bone density and the bone structure as a whole, affecting globally the biomechanical properties of the bone. In our case, the bisphosphonate is directly brought into the bone. Moreover, only a local region around the implant will be exposed to the drug. Thus, only the periimplant bone density and structure will be affected leading to a different biomechanical situation than in the case where the bisphosphonate was used in a systemic way. Those different biomechanical situation could be one explanation of the differences in bone structure observed after systemic or local bisphosphonate treatment. The zoledronate-related changes in the bone structure also strongly influenced the mechanical fixation of the implant. Indeed, the correlation between the histomorphometric parameters $\mathrm{Tm} . \mathrm{Tm} / \mathrm{TSL}$, Nd.Tm/TSL, Nd.Nd/TSL, and TSL was strong. Therefore, the narrowing of the weaved structure of bone trabeculae enhanced the fixation of the implant.

The $\mathrm{pH}$ of the zoledronate solution (used as sodium salt) was 6.8. Since the sodium salt is used, the $\mathrm{pH}$ is independent of the zoledronate concentration. The surface state of the HA has been checked by SEM, but no change due to Zoledronate grafting was observed (data not shown). The zoledronate was grafted by ion exchange with the phosphate ions from the HA [20]. Based on this data, the HA coating does not become saturated with bisphosphonate, but an equilibrium is created between the phosphate groups and the bisphosphonate groups. This explains the zoledronate solution concentration effect. The differences in zoledronate content of the coating, although the different bisphosphonate solutions had several orders of magnitude, can be explained by the fact that the ion exchange reaction is an equilibrium between the bisphosphonate groups and the phosphate groups in the coating.

Bisphosphonate, by affecting bone remodeling, could also block the bone repair process. The drug at too high concentrations could then have detrimental effects on the fixation of the implant over longer periods of time. Indeed, conflicting studies have reported that the use of bisphosphonate can interact with the repair of cracks and fractures, while other studies were unable to demonstrate this phenomena [17,21-23]. Specifically for the zoledronate, it has been shown that aminobisphosphonate (like zoledronate), due to the lower dosing, will not impair with the fractures and cracks repair [4]. A very encouraging result was obtained in a 7-year follow-up studies of alendronate treatment in osteoporotic women which did not show any adverse effects [36]. Long-term results for implants used as 
drug delivery systems should also show an increase in implant stability. Indeed, the present study was designed as proof of concept for increasing implant stability with a drug delivery system. The positive results obtained allow us to design now a long-term study.

\section{Conclusion}

In this study, we were able to demonstrate the effectiveness of the concept of using a local bisphosphonate delivery from a calcium phosphate coating in order to increase the mechanical fixation of an orthopedic implant. Moreover, we showed that the increase in peri-implant bone density is zoledronate concentration-dependent. The zoledronate release from the coating positively influences the structure of the trabecular bone and therefore the mechanical stability of the implant. We showed that the mechanical stability of an implant is correlated to the $20 \mu \mathrm{m}$ of bone around to the implant, advocating then in favor of a local delivery system. A long-term in vivo animal should then be performed to confirm these results which would open the way of an easy transformation of currently existing HA-coated implants. By grafting zoledronate onto the coating, their service life in patients could be increased.

\section{Acknowledgments}

This work was partially supported by the French Ministry of Research (ACI Technologies pour la Santé), the C.N.R.S. (Programme Matériaux Nouveaux Fonctionnalités Nouvelles), and the Fondation de l'avenir pour la recherche médicale appliquée. Partial support from the Région Pays de la Loire (CPER Biomatériaux S3) is also acknowledged. We thank Novartis Pharma Research (Basel) for a generous gift of . and J.R. Green (Novartis Pharma Research) for fruitful discussion. We thank Paul Pilet and Myriam Leroy for technical assistance.

\section{References}

[1] Adler E, Stuchin SA, Kummer FJ. Stability of press-fit acetabular cups. J Arthrolasty 1992;7:295-301.

[2] Ames BN. Assay of inorganic phosphate, total phosphate and phosphatases. In: Colowick SP, Kaplan NO, editors. Methods in enzymology, Orlando: Academic Press; p. 115-8.

[3] Arden-Cordone M, Siris ES, Lyles KW, Knieriem A, Newton RA, Schaffer V, et al. Antiresorptive effect of a single infusion of microgram quantities of zoledronate in Paget's disease of bone. Calcif Tissue Int 1997;60:415-8.

[4] Bartl R, Frisch B. Das bisphosphonat-Manual. Berlin, Germany: Wissenschaft; 2001.

[5] Bloebaum RD, Skedros JG, Vajda EG, Bachus KN, Constantz BR Determining mineral content variations in bone using backscattered electron imaging. Bone 1997;20:485-90.

[6] Chappard D, Legrand E, Pascaretti C, Basle MF, Audran M. Comparison of eight histomorphometric methods for measuring trabecular bone architecture by image analysis on histological sections. Microsc Res Tech 1999;45:303-12.

[7] Denissen H, Martinetti R, van Lingen A, van den Hooff A. Normal osteoconduction and repair in and around submerged highly bisphosphonate-complexed hydroxyapatite implants in rat tibiae. J Periodontol 2000;71:272-8.

[8] Denissen H, Montanari C, Martinetti R, van Lingen A, van den Hooff A. Alveolar bone response to submerged bisphosphonate-complexed hydroxyapatite implants. J Periodontol 2000;71:279-86.

[9] Elliott SN, McKnight W, Davies NM, MacNaughton WK, Wallace JL. Alendronate induces gastric injury and delays ulcer healing in rodents. Life Sci 1998;62:77-91.

[10] Epinette JA, Manley MT. Fifteen years of clinical experience with hydroxyapatite coatings in joint arthroplasty. Paris: Springer; 2004.

[11] Fleisch H. The bisphosphonate ibandronate, given daily as well as discontinuously, decreases bone resorption and increases calcium retention as assessed by $45 \mathrm{Ca}$ kinetics in the intact rat. Osteoporos Int 1996;6:166-70.

[12] Fleisch H. Bisphosphonates in bone disease, from the laboratory to the patient. The Parthenon Publisching Group.

[13] Fratzl P, Schreiber S, Roschger P, Lafage MH, Rodan G, Klaushofer $\mathrm{K}$. Effects of sodium fluoride and alendronate on the bone mineral in minipigs: a small-angle X-ray scattering and backscattered electron imaging study. J Bone Miner Res 1996;11:248-53.

[14] Goodman SB, Huie P, Song Y, Lee K, Doshi A, Rushdieh B, et al. Loosening and osteolysis of cemented joint arthroplasties. A biologic spectrum. Clin Orthop 1997;149-63.

[15] Hilding M, Ryd L, Toksvig-Larsen S, Aspenberg P. Clodronate prevents prosthetic migration: a randomized radiostereometric study of 50 total knee patients. Acta Orthop Scand 2000;71:553-7.

[16] Hyldstrup L, Flesch G, Hauffe SA. Pharmacokinetic evaluation of pamidronate after oral administration: a study on dose proportionality, absolute bioavailability, and effect of repeated administration. Calcif Tissue Int 1993;53:297-300.

[17] Hyvonen PM, Kowolik MJ. Influence of dichloromethylene bisphosphonate on the in vitro phagocytosis of hydroxyapatite particles by rat peritoneal exudate cells: an electron microscopic and chemiluminescence study. Ann Rheum Dis 1992;51:203-9.

[18] Inaoka T, Shuke N, Sato J, Ishikawa Y, Takahashi K, Aburano T, et al. Scintigraphic evaluation of pamidronate and corticosteroid therapy in a patient with progressive diaphyseal dysplasia (Camurati-Engelmann disease). Clin Nucl Med 2001;26:680-2.

[19] Iwase M, Kim KJ, Kobayashi Y, Itoh M, Itoh T. A novel bisphosphonate inhibits inflammatory bone resorption in a rat osteolysis model with continuous infusion of polyethylene particles. J Orthop Res 2002;20:499-505.

[20] Josse S, Faucheux C, Soueidan A, Grimandi G, Massiot D, Alonso B, et al. Chemically modified calcium phosphates as novel materials for bisphosphonate delivery. Adv Mater 2004;16:1423-7.

[21] Li J, Mashiba T, Burr DB. Bisphosphonate treatment suppresses not only stochastic remodeling but also the targeted repair of microdamage. Calcif Tissue Int 2001;69:281-6.

[22] Li J, Mori S, Kaji Y, Kawanishi J, Akiyama T, Norimatsu H. Concentration of bisphosphonate (incadronate) in callus area and its effects on fracture healing in rats. J Bone Miner Res 2000;15: $2042-51$

[23] Li J, Mori S, Kaji Y, Mashiba T, Kawanishi J, Norimatsu H. Effect of bisphosphonate (incadronate) on fracture healing of long bones in rats. J Bone Miner Res 1999;14:969-79.

[24] Little DG, Smith NC, Williams PR, Briody JN, Bilston LE, Smith EJ, et al. Zoledronic acid prevents osteopenia and increases bone strength in a rabbit model of distraction osteogenesis. J Bone Miner Res 2003;18:1300-7.

[25] Meraw SJ, Reeve CM. Qualitative analysis of peripheral peri-implant bone and influence of alendronate sodium on early bone regeneration. J Periodontol 1999;70:1228-33. 
[26] Meraw SJ, Reeve CM, Wollan PC. Use of alendronate in peri-implant defect regeneration. J Periodontol 1999;70:151-8.

[27] Mjoberg B. The theory of early loosening of hip prostheses. Orthopedics 1997;20:1169-75.

[28] Moilanen T, Stocks GW, Freeman MA, Scott G, Goodier WD, Evans SJ. Hydroxyapatite coating of an acetabular prosthesis. Effect on stability. J Bone Joint Surg Br 1996;78:200-5.

[29] Monkkonen J, Simila J, Rogers MJ. Effects of tiludronate and ibandronate on the secretion of proinflammatory cytokines and nitric oxide from macrophages in vitro. Life Sci 1998;62:L95-102.

[30] Motoie H, Nakamura T, O'Uchi N, Nishikawa H, Kanoh H, Abe T, et al. Effects of the bisphosphonate YM175 on bone mineral density, strength, structure, and turnover in ovariectomized beagles on concomitant dietary calcium restriction. J Bone Miner Res 1995;10:910-20.

[31] Onsten I, Carlsson AS, Ohlin A, Nilsson JA. Migration of acetabular components, inserted with and without cement, in onestage bilateral hip arthroplasty. A controlled, randomized study using roentgen stereophotogrammetric analysis. J Bone Joint Surg Am 1994; 76:185-94.

[32] Pandey R, Quinn JM, Sabokbar A, Athanasou NA. Bisphosphonate inhibition of bone resorption induced by particulate biomaterialassociated macrophages. Acta Orthop Scand 1996;67:221-8.

[33] Peter B, Zambelli PY, Guicheux J, Pioletti DP. In vitro evaluation of bisphosphonate and titanium particles effects on osteoblasts. J Bone Joint Surg Br 2004 [submitted for publication].

[34] Plotkin LI, Weinstein RS, Parfitt AM, Roberson PK, Manolagas SC, Bellido T. Prevention of osteocyte and osteoblast apoptosis by bisphosphonates and calcitonin. J Clin Invest 1999;104:1363-74.

[35] Roschger P, Fratzl P, Eschberger J, Klaushofer K. Validation of quantitative backscattered electron imaging for the measurement of mineral density distribution in human bone biopsies. Bone 1998;23: $319-26$.

[36] Sambrook PN, Rodriguez JP, Wasnich RD, Luckey MM, Kaur A, Meng L, et al. Alendronate in the prevention of osteoporosis: 7-year follow-up. Osteoporos Int 2004;15-6:483-8.

[37] Shanbhag AS, Hasselman CT, Rubash HE. The John Charnley Award. Inhibition of wear debris mediated osteolysis in a canine total hip arthroplasty model. Clin Orthop 1997;33-43.

[38] Soballe K, Hansen ES, Brockstedt-Rasmussen H, Hjortdal VE, Juhl GI, Pedersen CM, et al. Gap healing enhanced by hydroxyapatite coating in dogs. Clin Orthop 1991;300-7.

[39] Tengvall P, Skoglund B, Askendal A, Aspenberg P. Surface immobilized bisphosphonate improves stainless-steel screw fixation in rats. Biomaterials 2004;25:2133-8.

[40] Thiebaud D, Sauty A, Burckhardt P, Leuenberger P, Sitzler L, Green $\mathrm{JR}$, et al. An in vitro and in vivo study of cytokines in the acute-phase response associated with bisphosphonates. Calcif Tissue Int 1997;61:386-92.

[41] Wang BC, Lee TM, Chang E, Yang CY. The shear strength and the failure mode of plasma-sprayed hydroxyapatite coating to bone: the effect of coating thickness. J Biomed Mater Res 1993;27:1315-27.

[42] Wilkinson JM, Stockley I, Peel NF, Hamer AJ, Elson RA, Barrington NA, et al. Effect of pamidronate in preventing local bone loss after total hip arthroplasty: a randomized, double-blind, controlled trial. J Bone Miner Res 2001;16:556-64.

[43] Yaffe A, Kollerman R, Bahar H, Binderman I. The influence of alendronate on bone formation and resorption in a rat ectopic bone development model. J Periodontol 2003;74:44-50.

[44] Yoshinari M, Oda Y, Ueki H, Yokose S. Immobilization of bisphosphonates on surface modified titanium. Biomaterials 2001;22:709-15. 